\title{
Pattern laser vs laser point to point
}

\begin{abstract}
Diabetic retinopathy is one of the main causes of irreversible blindness in the world. Panphotocoagulation is the treatment of choice and has shown over the decades to reduce the incidence of blindness in these patients. However, when put into practice, these treatments are long, require several sessions, and are often painful for the patient. Technological advances have allowed the development of pattern laser, giving the possibility of performing a complete pan-photocoagulation in a single session and in half of the time. This article reviews some aspects of this treatment methodology compared to argon laser point to point.
\end{abstract}

Keywords: diabetic retinopathy, pan-photocoagulation, pattern laser, argon laser
Volume 7 Issue I - 2017

\author{
Stersovsky Marcelo, Diamint DV, Pagano \\ Boza C \\ CEMIR, Argentina
}

Correspondence: Stersovsky Marcelo, Honduras $55502^{\circ}$

floor apt 205, Autonomous city, Buenos aires, Argentina,

Tel +54I I4447859I, Email sterzovsky@gmail.com

Received: May 15, 2017 | Published: May 15, 2017

\section{Introduction}

Laser, along with surgery and injections of intravitreal substances, is one of the main treatments used in vitreoretinal-choroidal diseases. Within these, diabetic retinopathy and venous thrombosis are the 2 most frequent causes for which a patient may require a pan photocoagulation. This procedure consists of performing at least 1500 laser impacts outside the vascular arches. It is supported by many studies; some of them were published as long as 20 years ago, as for example the Diabetic Retinopathy Study. Thus, due to the high incidence of proliferative diabetic retinopathy and venous thrombosis, it is very common for the ophthalmologist treating these patients, usually the retinologist, to spend long periods of time so that the patients receive optimal treatment. However, since 2005 the laser in pattern is already an option. The mechanisms vary according to the brand, but ultimately the objective is that with a single shot, multiple impacts will be generated.

We must then have 3 considerations: 1- effectiveness, 2- adverse events and 3-comfort, both for the doctor and the patient. As for effectiveness, the bibliography is contradictory. A recent study ${ }^{1}$ in patients with proliferative diabetic retinopathy showed that the percentage of neovasal persistence with the laser in the pattern was $20 \%$ versus $2 \%$ with the argon laser, and in turn, the percentage of neovasal recurrence at 6 months was $67 \%$ for the standard laser versus $33 \%$ for the argon laser. On the other hand, ${ }^{2}$ other studies, one of which also evaluated patients with proliferative diabetic retinopathy 2 and another on retinopathy of prematurity, 3 did not demonstrated differences between both types of laser treatments. Regarding the adverse events, none of the 3 previously mentioned studies found differences. Finally, comfort was one of the main differences. It often happens that when treating patients with retinopathy of prematurity, treatment time is a decisive factor. The treatment time in this case was 15 minutes for the standard laser versus 40 minutes for the argon laser. ${ }^{3}$ A similar difference was observed in cases of proliferative diabetic retinopathy. ${ }^{2}$ This can bring important benefits in completing a pan-photocoagulation with fewer sessions and/or a greater potential number of treatable patients per hour, thus reducing turnaround delays and health expenditures.

\section{Conclusion}

The laser pattern provides greater comfort for the patient and the physician, without major adverse events, but appears to be less effective than performing point-to-point burns with argon laser. Surely with the perfection of this technology, the day will come when we achieve a complete treatment with 1 or 2 impacts.

\section{Acknowledgements}

None.

\section{Conflicts of interest}

The authors declare there are no conflicts of interest.

\section{References}

1. Chappelow AV, Tan K, Waheed NK, et al. Panretinal photocoagulation for proliferative diabetic retinopathy: pattern scan laser versus argon laser. Am J Ophthalmol. 2012;53(1 ):137-142.

2. Muqit MM, Marcellino GR, Henson DB, et al. Single-session vs multiple-session pattern scanning laser panretinal photocoagulation in proliferative diabetic retinopathy: The Manchester Pascal Study. Arch Ophthalmol. 2010;128(5):525-533.

3. Tereshchenko AV, Belyř IuA, Volodin PL, et al. Pattern retinal laser coagulation in treatment of aggressive posterior retinopathy of prematurity. Vestn Oftalmol. 2010;26(6):38-43. 